Altai State University

Acta 3iologica Gibirica

Journal of Biology

Founded in 2015 www.asu.ru

ISSN 2412-1908

Acta Biologica Sibirica, 2017, 3(4), 93-98

\title{
Change of parametersof physiological state in Veronica spicata spicata L. S.str. in the flowering period under the influence of coal and rock dust in the territory of the Karakan Range (Kemerovo Region)
}

\author{
A.Yu. Grebennikova, P.A. Kosachev, M.M. Silanteva \\ Altai State University, Barnaul, Russia \\ grebennikova.ann@mail.ru; pakosachev@yandex.ru; msilan@mail.ru
}

\begin{abstract}
The influence of technogenesis associated with the development of the coal mining industry is multifaceted. One of the factors affecting the natural coal mining in the open method is coal and rock dust. To assess the response of plants to this effect, information was used on the change in the concentration of pigments obtained for three field seasons (2015-2017 g) obtained by spectrophotometry. The article gives information on the change in the content of chlorophylls in the leaves of one of Veronica spicata spicata L. s.str. veronica observation objects, which is a species with wide ecological amplitude. It is shown that the variability of the chlorophyll a and b concentrations in Veronica spicata serves as a reliable indicator in determining the degree of negative impact of coal and rock dust on plants.
\end{abstract}

Key words: Veronica spicata L.s.l.; spectrophotometry; ecological monitoring; bioindication

\section{Изменение параметров физиологического состояния у Veronica spicata spicata L. s.str. в период цветения под воздействием угольной и породной пыли на территории Караканского хребта (Кемеровская область)}

\author{
А.Ю. Гребенникова, П.А. Косачев, М.М. Силантьева \\ Алтайский государственный университет, Барнаул, Российская Федерация \\ grebennikova.ann@mail.ru; pakosachev@yandex.ru; msilan@mail.ru
}


Grebennikova, A.Yu. et al. (2017). Change of parametersof physiological.... Acta Biologica Sibirica, 2017, 3(4), 93-98

пигментов, полученные за три полевых сезона (2015-2017 г) методом спектрофотометрии. В статье приводятся сведения об изменении содержания хлорофиллов в листьях одного из объектов наблюдения вероники Vеronica spicata L. spicata L. S.str. который является видом с широкой экологической амплитудой. Показано, что изменчивость концентрации хлорофилла $a$ и $b$ y Veronica spicata служит достоверным индикатором при определении степени негативного воздействия угольной и породной пыли на растения.

Ключевые слова: Вероника колосистая; спектрофотометрия; экологический мониторинг; биоиндикация

\section{Введение}

На юге Западной Сибири в Кузбассе (Кемеровская область) весь XX век происходил активный техногенез, связанный с развитием угледобывающей промышленности, как основной отрасли народного хозяйства. Процесс трансформации окружающей среды под воздействием различных видов технической деятельности человека привел к разрушению и деградации природной среды на значительной площади региона. В ряде мест изменились формы рельефа, ухудшился гидрологический режим местностей, изменился геохимический сток, усилилось шумовое и пылевое воздействие, произошло резкое снижение биологического разнообразия. Расширение районов угледобычи в настоящее время привело к тому, что карьеры и шахты оказались в непосредственной близости от территорий с наиболее сохраненной естественной (природной средой), рядом с особо охраняемыми природными территориями (ООПТ), такими, как заказник «Караканский». Государственный природный заказник был создан на одноименном хребте в 2012 г. (площадь 1115 тыс. га). На его территории представлены в основном степные и лесные экосистемы. Основной угрозой биологическому разнообразию заказника «Караканский» является техногенное воздействие со стороны угледобывающих предприятий в виде угольной и породной пыли, которая образуется при открытом способе добыче угля (Lashchinsky, 2011; Lashchinsky, Makunina, 2011).

Воздействие угольной и породной пыли на растительный покров, и биологическая активность зависит от её происхождения и химического состава. Качественный состав угольной пыли, как правило, определяется составом угольного пласта, а породной - геохимическим составом вмещающих пород (Romanchenko, 2009). Частицы пыли, разнородные по форме и происхождению оказывают эффект механического запыления листа растения и, как следствие, наблюдается снижение фотосинтетической активности и физиологических показателей (концентрации пигментов) растений в фитоценозах, находящихся в зоне воздействия. Кроме механического запыления поверхности листовой пластины, угольная и породная пыль оседает и накапливается на поверхности почвы, оказывая негативное влияние на химический состав и питание растений и условия их произрастания.

Оценка состояния видов растений под воздействием стресс-факторов (в нашем случае это угольная и породная пыль) базируется чаще всего на морфологических и цитогенетических критериях (Golovko, 2007). Физиологические показатели используются реже. Но, именно физиологическая пластичность во многом предопределяет перспективы выживания и продуктивности особи. Эта биологическая особенность определяется тем, что физиологические процессы у растений в значительной степени определяются условиями окружающей среды. Поэтому эколого-физиологическая характеристика особенно значима при определении устойчивости растений к экстремальным условиям среды (Bioindikatsia ..., 1988). Одними из важнейших биоиндикационных показателей у растений на физиологическом уровне являются особенности протекания фотосинтеза, который чувствительно реагирует на всякое изменение факторов внешней среды (Bioindikatsia ...., 1988).

Для проведения исследований на территории Караканского хребта было выбрано 5 видов высших сосудистых растений: Bromopsis inermis, Fragaria viridis, Phlomis tuberosa, Allium nutans, Veronica spicata, которые в большем объеме представлены на всех мониторинговых площадках и отвечающие всем требованиям, предъявляемым к видам-индикаторам: распространены на всей изучаемой территории и на мониторинговых площадках повсеместно, характерны для природной зоны, где располагаются мониторинговые площадки. Биология (морфология, физиология, биохимия и др.) видов-индикаторов хорошо изучена; надземные органы остаются зелеными весь вегетационный период и не поражаются грибными и бактериальными болезнями. Виды чувствительны к воздействию стресс-фактора (угольной и породной пыли).

Одним из наиболее эффективных видов-индикаторов является вероника колосистая (Veronica spicata L. S.I. (Plantaginaceae). Это лесостепной вид, широко распространенный от западных берегов оз. Байкал до атлантического побережья Европы. Предполагается гибридогенное происхождение вида в эпоху плейстоценовых оледенений в результате контактов среднеазиатско-алтайского вида V. porphyriana с понтическим ксерофильным видом V. barrelieri, происходившие во время распространения первого вида на запад в период формирования евразийских степей (Tsvelev, 1981; Kosachev, 2011). На территории Южной Сибири известно 3 подвида V. spicata: V. spicata subsp. kamelinii Kosachev, V. spicata subsp. paczoskiana (Klok.) Kosachev и V. spicata subsp. spicata. Первый подвид известен только из соснового леса северного макросклона г. Синюха Курьинского района Алтайского края. Второй подвид обитает на равнине в сосновых лесах Алтайского края, Новосибирской, Томской и Тюменской областях. Последний типовой подвид, который относится к объекту нашего исследования, в сосновых лесах не встречается, а распространен только на открытых степных участках, как на равнине, так и в предгорьях (Kosachev, 2003, Kosachev, Ebel, 2010). 
Grebennikova, A.Yu. et al. (2017). Change of parametersof physiological.... Acta Biologica Sibirica, 2017, 3(4), 93-98

На всем протяжении своего ареала V. spicata subsp. spicata имеет 2 цитотипа, В Азии диплоидный (2n = 34) и в Европе - тетраплоидный $(2 \mathrm{n}=68)$ (Kosachev, Albach, Ebel, 2015).

Вид ранее использовался в качестве объекта мониторинга состояния окружающей среды. Было установлено, что растения, произрастающие в условиях промышленного воздействия, адаптируются к загрязненной промышленными выбросами газовой среде через увеличение суммы флавоноидов в фитомассе, что свидетельствует об изменении хода метаболических процессов и химического состава растений (Nemershina et al., 2009). В ряде современных работ по экологической физиологии растений объектом исследования является Veronica spicata L. s.l. (Suomi et al., 2002; Nikolova, Gevrenova, 2006; Kostadinova et al., 2007; Crian et al., 2010; PintoZevallos et al., 2013; Kremer, 2013). Установлено, что в клетках и тканях вероники колосистой под воздействием стресс-факторов накапливаются различные летучие органические соединения, которые повышают устойчивость растения. Следовательно, растения выбранного вида могут служить индикаторами длительного антропогенного негативного воздействия, в том числе угольной и породной пыли как комплексного стресс-фактора.

\section{Материалы и методы}

Для проведения исследований заложены две мониторинговые площадки (МП) на территории Караканского хребта в Кемеровской области (МП «Каракан-1», МП «Каракан-2») и одна площадка на территории Алтайского края МП «Парфеново» (контроль), где отсутствует воздействие угольной и породной пыли. МП «Каракан-1», выделенная в качестве наиболее подвергающейся негативному воздействию угольной и породной пыли, находится на расстоянии 900 м от угольного разреза и по дороге к угольному складу ПАО «Кузбасская топливная компания».

Для измерения количества хлорофилла $a u b$ в срединных листьях спектрофотометрическим методом использован спектрофотометр ПЭ-5400 (Россия) при длинах волн, соответствующих максимумам поглощения хлорофиллов a (665нм) и $b$ (649 нм), с последующим расчетом концентрации пигментов по уравнениям Ветштейна и Хольма для 96\%-го спирта.

\section{Результаты и их обсуждение}

При определении степени негативного воздействия угольной и породной пыли на растения заложенных мониторинговых площадок проводилась статистическая обработка полученных данных с использованием критерия Вилкоксона (Манна-Уитни) - один из наиболее известных непараметрических статистических критериев (Orlov, 1990). Его выбор был обусловлен необходимостью установления различия между выбранными мониторинговыми площадками. Если бы различия не было установлено, то для дальнейшего изучения две рассматриваемые площадки на территории Караканского хребта необходимо было объединить в одну. Таким же образом был проведен отбор мониторинговой площадки «Контроль» (табл. 1, 2).

Нулевая гипотеза в нашем случае состояла в том, что центры распределений, из которых происходят сравниваемые выборки, смещены относительно друг друга на величину $\mu=0$ (т.е. они одинаковы в статистическом смысле).

Статистическая обработка данных исследований показала, что мониторинговые площадки (МП «Каракан-1», МП «Каракан-2»), заложенные на территории Караканского хребта, отличаются незначительно и ни одна из них не может быть назначена в качестве контроля, включая участок, находящийся на территории заказника (МП «Каракан-2»). Но и объединить их невозможно, так как разница значительная. Вследствие этого, мониторинговая площадка в качестве контрольной (МП «Парфеново») была заложена на территории Алтайского края для полного исключения воздействия угольной и породной пыли. Для исключения влияние различной степени увлажнения, при выборе мониторинговых площадок проводится измерение влажности и температуры почвы.

Было установлено, что участки, выбранные для целей мониторинга репрезентативны, выбор площадки «Контроль» - оправдан. Кроме того, для изучения разницы в концентрациях хлорофилла $а$ и в были построены диаграммы размаха, которые используют для визуальной экспресс-оценки разницы между группами данных. При статистической обработке данных, полученных за три года исследований, были рассчитаны медианы концентраций хлорофилла а и в (рис. 1).

Таблица 1. Результат статистической обработка полученных данных по концентрации хлорофилла а с использованием критерия Вилкоксона (Манна-Уитни)

Veronica spicata

Июнь

МП

Каракан-1

Каракан-2

Каракан-1

Каракан-2
Каракан-1

12,5

20

$100,0 \%$

$15,1 \%$
Каракан-2

5

12,5

$15,1 \%$

$100,0 \%$
Коэффициент

W

$\mathrm{p}$ 


$\begin{array}{lllll}\text { Июль } & \text { Каракан-1 } & \text { Каракан-2 } & \text { Парфеново } & \text { Коэффициент } \\ \text { МП } & 12,5 & 0 & 0 & \\ \text { Каракан-1 } & 25 & 12,5 & 6 & \text { W } \\ \text { Каракан-2 } & 25 & 19 & 12,5 & \\ \text { Парфеново } & 100,0 \% & 0,8 \% & 0,8 \% & \\ \text { Каракан-1 } & 0,8 \% & 100,0 \% & 22,2 \% & \mathrm{p} \\ \text { Каракан-2 } & 0,8 \% & 22,2 \% & 100,0 \% & \\ \text { Парфеново } & & & & \text { Коэффициент } \\ \text { Август } & \text { Каракан-1 } & \text { Каракан-2 } & \text { Парфеново } & \text { К } \\ \text { МП } & 12,5 & 5 & 0 & \\ \text { Каракан-1 } & 20 & 12,5 & 6 & \\ \text { Каракан-2 } & 25 & 19 & 12,5 & \text { р } \\ \text { Парфеново } & 100,0 \% & 15,1 \% & 0,8 \% & \\ \text { Каракан-1 } & 15,1 \% & 100,0 \% & 22,2 \% & \\ \text { Каракан-2 } & 0,8 \% & 22,2 \% & 100,0 \% & \\ \text { Парфеново } & & & \end{array}$

Примечание: в таблице использованы следующие значения

W - статистика теста;

P - вероятность случайным образом получить значение W, равное или превышающее наблюдаемое значение (при условии истинности нулевой гипотезы)

Таблица 2. Результат статистической обработка полученных данных по концентрации хлорофилла $b$ c использованием критерия Вилкоксона (Манна-Уитни)

\section{Veronica spicata}

Июнь

МП

Каракан-1

Каракан-2

Каракан-1

Каракан-2

Июль

$\mathrm{M \Pi}$

Каракан-1

Каракан-2

Парфеново

Каракан-1

Парфеново

Август

МП

Каракан-1

Каракан-2

Парфеново

Каракан-1

Каракан-2

Парфеново
Каракан-1

12,5

22

$100 \%$

$6 \%$

\section{Каракан-1}

12,5

11

18

$100 \%$

$84 \%$

$31 \%$

Каракан-1

12,5

25

25

$100 \%$

$1 \%$

$1 \%$
Каракан-2

3

12,5

$6 \%$

$100 \%$
W
Каракан-2

Примечание: в таблице использованы следующие значения
Каракан-2

14

12,5

21

$84 \%$

$100 \%$

$10 \%$

Каракан-2

0

12,5

25

$1 \%$

$100 \%$

$1 \%$
Парфеново

7

4

12,5

$31 \%$

$10 \%$

$100 \%$

Парфеново

0

0

12,5

$1 \%$

$1 \%$

$100 \%$
W

$\mathrm{P}$

W - статистика теста;

P - вероятность случайным образом получить значение W, равное или превышающее наблюдаемое значение (при условии истинности нулевой гипотезы) 


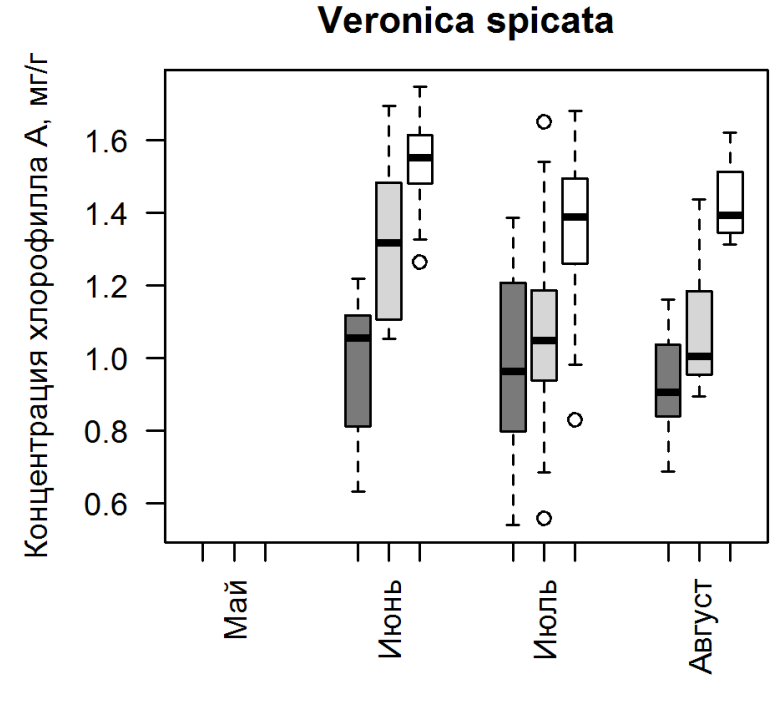

Каракан $1 \quad \square$ Каракан $2 \quad \square$ Парфёново

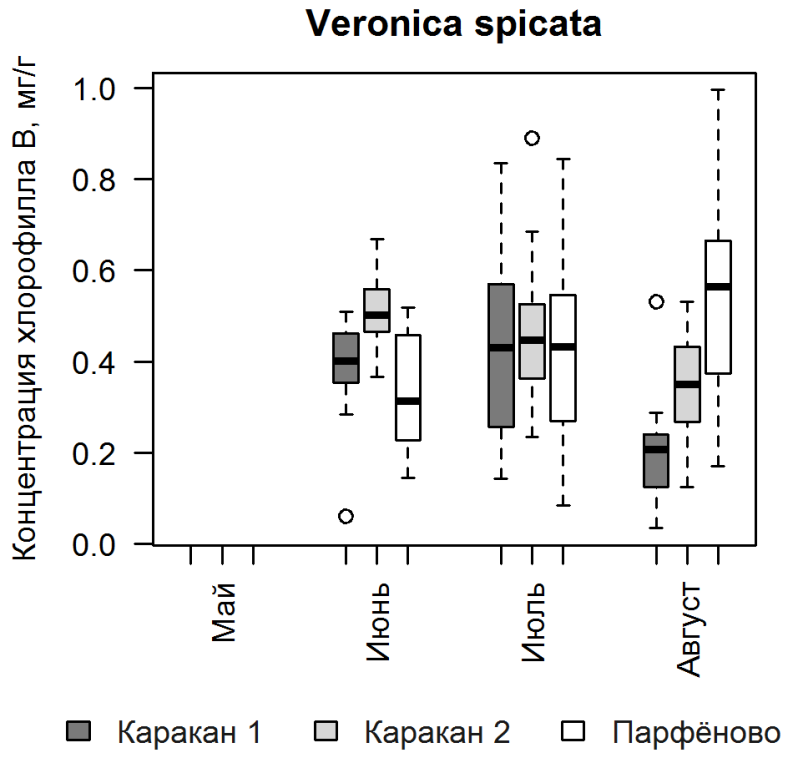

\section{Рис. 1. Изменчивость концентрации хлорофиллов a (а) и b (б) в листьях Veronica spicata на мониторинговых площадках за 2015-2017 вегетационные периоды}

Изучение динамики хлорофилла $a$ и $b$ по трем годам исследований в листьях Veronica spicata показало, что для всех мониторинговых площадок (МП) отмечено снижение концентрации хлорофилла $a$ и в в августе по сравнению с июнем, что связано с понижением среднесуточных температур и, как следствие, общим угасанием растений (конец вегетации). В период летней депрессии роста растений (вторая половина июня - первая половина июля), характерной для степной и лесостепной зоны, на всех мониторинговых площадках отмечено значительное снижение концентрации хлорофилла $a$, В тоже время средняя концентрация хлорофилла $b$ была на одном уровне для всех исследуемых площадок - средние значения этого признака были сближены.

Следует отметить, что для образцов на мониторинговой площадке «Каракан-1» концентрация хлорофилла $a$ в каждом месяце снижена практически в 3 раза по сравнению с контролем, что говорит о нахождении образцов в наиболее неблагоприятных условиях, в которых влияние на фотосинтетический аппарат оказывает не только снижение среднесуточных температур, но и угольная и породная пыль.

По результатам исследования для всех отобранных двудольных видов-индикаторов в течение рассматриваемых вегетационных периодов 2015-2017 гг. характерно уменьшение содержания хлорофилла $а$ в фазе начала вегетации (июнь) по сравнению с фазой вегетации после цветения (август). Hо, Veronica spicata является наиболее устойчивым видом в этом отношении, снижение хлорофилла $а$ в листьях образцов этого вида составляло не более $4 \%$.

Наблюдалась изменчивость концентрации хлорофилла $a$ и $b$ в листьях образцов Veronica spicata на всех мониторинговых площадках, включая контроль, не испытывающей загрязнения угольной и породной пылью в течение вегетационного периода. В то же время отмечено снижение содержания хлорофилла $a$ и $b$ у растений на МП «Каракан-1», МП «Каракан-2» по сравнению с площадкой «Парфеново» (контроль). Самые низкие показатели содержания хлорофилла $a$ и $b$ в листьях образцов всех видов, а также их резкое уменьшение в летний сезон по сравнению с контролем характерно для МП «Каракан-1», что свидетельствует о выраженном кумулятивном воздействии загрязнения, вызванного угольной и породной пылью.

Анализ данных, полученных на мониторинговых площадках подверженных воздействию угольной и породной пыли по сравнению с контролем доказывает, что Veronica spicata является видом с широкой экологической амплитудой. На мониторинговых площадках «Каракан-1» и «Каракан-2» отмечено хроническое воздействие угольной и породной пыли. Однако изменение физиологических и биохимических процессов у вероники происходит гораздо позже, чем у чувствительных растений-индикаторов, которые реагируют на стресс значительным отклонением от жизненных норм. Тем не менее, изменчивость концентрации хлорофилла $a$ и $b$ у Veronica spicata служит достоверным индикатором при определении степени негативного воздействия угольной и породной пыли на растения.

\section{References}

Bioindikatsia zagrjazneniy nazemnych ekosistem (1988). P. Shubert (edit.). Moskau: Mir, 350. (in Russian)

Golovko, T.K., Tabalenkova, G.N., Dymova, O.V. (2007). Pigment apparatus of Subpolar Ural plants. Botan. Zhurn., 92, 11, 1732-1741. (in Russian) 
Kosachev, P.A. (2003) Review of the section Pseudolysimachium W.D.J. Koch (genus Veronica L., Scrophulariaceae) in Altai mountains. Turczaninowia, 6, 1, 11-33. (in Russian)

Kosachev, P.A. (2011). Composition of the genus Veronica L. (Plantaginaceae Juss.) Altai-Sayan mountain country. Proceedings of the 10h International Scientific and Practical Conference (Barnaul, 2011) Problems of Botany of South Siberia and Mongolia, 68-71. (in Russian)

Kosachev, P.A., Ebel, A.L. (2010). Notes on Veronica L. in Siberia. Animadversiones systematicae ex Herbario Kryloviano Universitatis Tomskensis, 102, 9-16. (in Russian)

Lashchinsky, N.N. (2011). Phisiko-geographichesky ocherk. Rastitel'ny mir Karakanskogo hrebta, 10-125. (in Russian)

Lashchinsky, N.N., Makunina, N.I. (2011). Rastitel'nost'. Rastitel'ny mir Karakanskogo hrebta, 18-25. (in Russian)

Neverova, O.A. (2001). Bioekologicheskaja otsenka zagrjaznenija atmosphernogo wosduha po sostojaniju drevesnyh rasteniy. Nowosibirsk: Nauka, 51-67. (in Russian)

Nemershina, O.N. (2009). O nekotoryh aspektah ratsional'nogo ispol'zovanija lekarstvennyh rasteniy Predural'ja. Izvestija OGAU, 2(22), 308-311. (in Russian)

Orlov, A.I. (1990). O perestroyke statisticheskoy nauki i ee primeneniy. Westnik statistiki, 1, 65-71. (in Russian)

Romanchenko, S.B. (2009). Kompleksnye issledovanija phraktsionnogo sostava ugol'noy pyli. Gorny inphormatsionnoanalitichesky bjulleten', 12, 197-209.

Tsvelev, N.N. (1981). Veroniki (Veronica L.) iz rodstva V. spicata L. i nekotorye voprosy philogenii etogo roda. Bjull. MOIP, otd. boil., 86, 6, 82-92.

Crian, G., Vlase, L., Balica, G., Muntean, D., Stefanescu, C. Paltinean, R. Tamas, M. Leucuta L. (2010). LC/MS analysis of aucubin and catalpol of some Veronica species. Farmacia, 58. 237-242.

Kostadinova, E.P., Kostadinova, E.P., Alipieva, K.I., Kokubun, T., Taskova, R.M., Handjieva, N.V. (2007). Phenylethanoids, iridoids and a spirostanol saponin from Veronica turrilliana. Phytochemistry, 68, 1321-1326.

Kremer, D., Kosir, I.J., Kosalec, I. (2013). Investigation of chemical compounds, antioxidant and antimicrobial properties of Teucrium arduini L. (Lamiaceae). Curr Drug Targets, 14, 1006-1014.

Kosachev, P.A., Albach, D., Ebel, A.L. (2015). Check-list of Veronica subg. Pseudolysimachium of Siberia. Turczaninowia, 18(3), 84-95.

Nikolova, M., Gevrenova, R. (2006). A HPLC analysis on interpopulational variations in the flavonoid composition of Veronica chamaedrys. Int. J. Bot., 2, 7-10.

Pinto-Zevallos, D.M., Hellén, H., Hakola. H. (2013). Induced defenses of Veronica spicata: Variability in herbivoreinduced volatile organic compounds. Source: Phytochemistry Letters, 6, 4, 653-656.

Suomi, J., Wiedmer, S.K., Jussila, M., Riekkola, M.L. (2002). Analysis of eleven iridoid glycosides by micellar electrokinetic capillary chromatography (MECC) and screening of plant samples by partial filling (MECC)-electrospray ionization mass spectrometry. J. Chromatogr., A 970, 287-296.

\section{Citation:}

Grebennikova, A.Yu., Kosachev, P.A. Silanteva, M.M. (2017). Change of parametersof physiological state in Veronica spicata spicata L. s.str. in the flowering period under the influence of coal and rock dust in the territory of the Karakan Range (Kemerovo Region). Acta Biologica Sibirica, 3 (4), 93-98.

Submitted: 11.07.2016. Accepted: 04.09.2017 cross ref $\underline{\text { http://dx.doi.org/10.14258/abs.v3i4.3635 }}$

(C) 2017 by the authors. Submitted for possible open access publication under the terms and conditions of the Creative Commons Attribution (CC BY) license (http://creativecommons.org/licenses/by/4.0/). 